' Universidade Federal do Rio de Janeiro (UFRJ), Escola de Serviço Social,

\title{
MEMÓRIA DA ESTERILIZAÇÃO FEMININA: UM ESTUDO GERACIONAL
}

Este texto discute dados de pesquisa qualitativa realizada em 20 I I e 20 I $2 \mathrm{com}$ mulheres entre 50 e 70 anos de idade a respeito da prática da esterilização

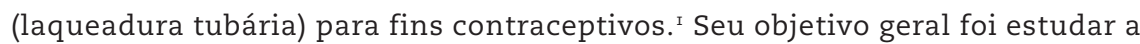
introdução da esterilização como forma de contracepção no Brasil, o que ocorre a partir dos anos i960 e I970, expandindo-se fortemente nas duas décadas seguintes. Neste artigo apresentarei os dados relativos às entrevistas sobre trajetória reprodutiva/contraceptiva concedidas por I5 mulheres moradoras da Região Metropolitana do Rio de Janeiro (capital e Baixada Fluminense) que tiveram de um a três filhos, sendo o primeiro por volta dos 20 anos. Elas foram esterilizadas em torno dos 30 anos de idade e, ao longo da vida, fizeram uso de algum método contraceptivo, mesmo que com percalços. As entrevistadas têm níveis de escolaridade/ocupação distintos. No conjunto, temos uma arquiteta, professoras, enfermeiras, operárias, donas de casa e empregadas domésticas. Nos relatos daquelas com escolaridade mais baixa foram mencionados aborto e roteiro contraceptivo mais restrito. Trabalhar com suas trajetórias permitiu a compreensão dos significados por elas atribuídos aos percursos de suas vidas, articulando valores e ações com contextos sociais mais amplos. Os resultados dessa pesquisa apontam para duas questões que serão desenvolvidas: a dimensão relacional que marcou a decisão pela esterilização e a produção, por essas mulheres, de memórias sobre a reprodução e a contracepção.

Segundo Caetano (2010: A24), em matéria publicada no jornal O Estado de S. Paulo, em maio de 2010 , 
A regulação da fecundidade se deu, principalmente, pelo aumento do uso da pílula e da laqueadura tubária. Os dois métodos eram empregados por $54,7 \%$ das mulheres unidas em idade reprodutiva em 1986 e por $60,8 \%$ delas em I996. Porém, em I986 havia I,I mulher laqueada para cada uma que usava pílula. Em I996, para cada mulher usando a pílula, duas estavam laqueadas. Esse quadro se configurou na ausência de programas públicos de planejamento familiar, o que fez da farmácia a principal fonte de obtenção da pílula e do parto cesáreo em hospital público a forma de se obter a laqueadura paga "por fora" ou "de favor".

A Pesquisa Nacional de Demografia e Saúde de 2006 (PNDS-2006) nos possibilita conhecer, por meio da comparação de suas informações com as pesquisas de I986 e I996, o quadro de algumas alterações significativas no campo da sexualidade, das relações de gênero e da reprodução no Brasil contemporâneo. Uma das questões mais interessantes levantada pela análise dos dados que obtivemos é o lugar fundamental ocupado pela geração dos anos I970 nas mudanças em relação ao comportamento sexual e reprodutivo das brasileiras (Wong \& Perpétuo, 2009). As mulheres que iniciam sua vida sexual nos anos I970 são aquelas que terão menos filhos em relação às coortes anteriores. Comparadas também com as coortes mais antigas, são aquelas que reduziram significativamente as chances de ter filhos na faixa dos 25-30 anos de idade. Depois de I970, o padrão reprodutivo da mulher brasileira se modifica definitivamente: o número final de filhos por mulher cai, e as taxas de fecundidade sofrem ajustes. Há diminuição dessa taxa em praticamente todas as faixas etárias e estabilidade na faixa etária mais jovem.

De acordo com Vieira (2002), a esterilização feminina começou a ser realizada no século XIX como medida eugênica, mas somente a partir dos anos I960 a técnica foi aperfeiçoada e difundida. Molina (I 999) argumenta que foi a partir dos anos I930, com a introdução da penicilina, que as cirurgias de esterilização foram ampliadas. Seu uso, porém, continuava ligado a motivos eugênicos até que, após a Segunda Guerra Mundial e em face da crítica à eugenia, a prática da esterilização teria sido abandonada para ressurgir nos anos I960. Esse ressurgimento teria sido acompanhado pela difusão da preocupação com o controle populacional, sobretudo nos países pobres e pela aplicação da laparoscopia e da minilaparotomia, ${ }^{2}$ técnicas consideradas menos arriscadas, porque menos invasivas, e mais efetivas para a realização da esterilização feminina. "A esterilização reaparece como solução para o controle da fertilidade agora sob nova condição, tomando a forma de uma escolha voluntária, individual, predominantemente uma decisão da mulher legitimada pela medicina" (Vieira, 2002: 65).

No Brasil, durante as décadas de 1970 e I980, período que se inclui no da ditadura militar, um número significativo de mulheres em idade reprodutiva começou a adotar a esterilização como forma de evitar filhos, em contexto histórico marcado pela simultânea ilegalidade e acusação moral ${ }^{3}$ dessa prática. Segundo Fonseca Sobrinho (I993), a ditadura militar tratou de forma ambígua o tema do controle de natalidade no território nacional. A postura vigente unia 
preocupações pró-natalistas, sustentadas pela ideia de crescimento populacional visando à ocupação de territórios, com a tolerância à presença de organizações internacionais, como a Sociedade Civil do Bem Estar Familiar - Bemfam, voltadas para a disseminação de métodos contraceptivos, e cujo discurso dominante era o da redução da população nos países periféricos como instrumento de combate à pobreza e à violência urbana (Alvarenga \& Schor, I998). Os anos I 970 e I 980 são também aqueles marcados pela forte mobilização do movimento feminista no Brasil e no mundo. Momento, aliás, atravessado por polêmicas internas ao próprio movimento, entre elas questões a respeito dos limites ao controle de natalidade em países periféricos como o nosso (Sarti, 200I). Vinte anos depois, já na década de I990, em atmosfera marcada pelo debate da saúde reprodutiva como direito humano fundamental, o Brasil adotará a Lei de Planejamento Familiar, pela qual a prática da esterilização voluntária (feminina e masculina) é nacionalmente regulamentada e o sistema público de saúde passa a oferecer esse serviço no quadro de uma política mais ampla de educação sexual e planejamento familiar.

O tema da esterilização feminina não é novo na pesquisa acadêmica; ao contrário, desde os anos I980 investigações sobre o assunto são realizadas no campo das ciências sociais, da história, da demografia e da saúde coletiva. No Brasil a literatura pertinente tem-se em geral concentrado em três aspectos: a relativização da ideia de autonomia feminina no campo reprodutivo, a relação hierárquica e moralizante entre médicos e pacientes, e a identificação, no país, de uma "cultura da esterilização feminina" que aponta para excessiva medi-calização da vida reprodutiva e, em particular, do corpo feminino. Essa medicalização em excesso, no entanto, nos faz conviver com índices elevados de mortalidade materna, ${ }^{4}$ o que desqualifica a medicalização e aponta para graves problemas de saúde das mulheres no Brasil. Quando a análise engloba a questão populacional, como é o caso das abordagens feitas no campo da demografia, soma-se a esses aspectos a influência das políticas públicas que modernizaram o país a partir de começo dos anos I980, como indica a clássica e pioneira análise de Vilmar Faria (I989) sobre o assunto. De acordo com esse autor, a despeito de o Estado brasileiro não ter adotado uma política explícita de regulação da fecundidade até o começo da década de I980, outros vetores institucionais, como as políticas de crédito ao consumidor, de telecomunicações, de previdência e de atenção à saúde, geraram impactos não previstos sobre a regulação da fecundidade no Brasil. A partir dos anos I990, as pesquisas demográficas no país têm acompanhado com atenção o impacto da introdução da política de planejamento familiar sobre a qualidade da saúde das mulheres, a adoção e o acesso a diferentes práticas contraceptivas por ambos os sexos e a manutenção da baixa taxa de fecundidade nacional, apesar de sua diversificada distribuição nos diferentes segmentos etários em idade reprodutiva (Berquó \& Cavenaghi, 2003). 
As análises nacionais que se preocuparam em registrar o ponto de vista das mulheres sobre a esterilização feminina, utilizando metodologia mais qualitativa de pesquisa, como os trabalhos de Joana Maria Pedro (2003), Luzinete Minella (2005), Lucila Scavone (2004), Suzanne Serruya (I996), Anne Dalsgaard (2006), Simone G. Diniz et al. (200I) e, mais recentemente, Cristiane da Silva Cabral (20I I), apontam para a complexidade de sentidos que a esterilização pode adquirir na vida das mulheres. Essas análises trouxeram à tona os problemas, dilemas e contradições que o desejo de não ter mais filhos pode trazer para as mulheres em diferentes situações de vida. Em geral, os estudos distribuem-se pelas diversas regiões do país, com predomínio de pesquisas que abordam a esterilização cirúrgica em mulheres de baixa renda e de pouca escolaridade. Uma característica comum a esses trabalhos é problematizar o binômio escolha-determinismo quando se trata de compreender as maneiras como as mulheres manejam a reprodução. Em especial nos trabalhos de Dalsgaard e de Cabral, em que se consideram as relações cotidianas das mulheres nas famílias e nas redes de vizinhança, ressaltam-se a complexidade da "decisão pela esterilização" e os múltiplos significados que a cirurgia pode ter entre as mulheres. Os processos de negociação da esterilização envolvem aspectos diferentes: considerações sobre a maternidade, percepções sobre o parceiro, avaliações a respeito dos projetos futuros de vida. Os estudos apontam para a importância da circulação das mulheres na rede médica, suas responsabilidades no interior da família (com o cônjuge e os filhos) e as relações com outras mulheres da parentela como aspectos presentes no processo de tomada de decisão e realização da esterilização.

Embora muitas pesquisas já tenham sido desenvolvidas sobre o tema, meu objetivo ao revisitá-lo foi o de incorporar nessa tradição de estudos a perspectiva da memória e das gerações. Nesse sentido, a experiência contraceptiva e, mais particularmente, a experiência com a prática da esterilização se constitui em memória da reprodução por meio das narrativas femininas. A geração entrevistada pode ser classificada como "geração pílula", segundo Joana Maria Pedro (2003: 25I):

A vida reprodutiva da "geração pílula" começava com as pílulas, em geral acompanhada de enjoos e problemas de circulação sanguínea, ou com o uso da tabelinha e do preservativo masculino; a seguir, passava pela laqueadura e, por fim, pela histerectomia e retirada dos ovários, prosseguindo com a reposição hormonal. ${ }^{5}$

Em primeiro lugar, é importante observar que as mulheres estão rememorando, ao longo da entrevista, o processo decisório e todos os elementos que elas tiveram que mobilizar para realizar a interrupção do ciclo reprodutivo. Essa memória é aqui transformada em relato oral. No ato de narrar acontecimentos do passado, é inevitável a presença do presente, que contribui para a seletividade daquilo que se coloca em relato e daquilo que dele se ausenta 
(Halbwachs, 2006; Pollak, I989), além do sentido de coerência a que o formato testemunhal obriga (Bourdieu, 2006). Nas sociedades moderno-contemporâneas (Velho, I994), a ênfase colocada sobre o individualismo como valor é a condição cultural e política de emergência e valorização dos modelos narrativos em primeira pessoa. A construção de projetos de vida necessita da memória e de sua colocação em discurso. Essa articulação entre memória e narrativa atribui sentido às trajetórias individuais. Segundo Beatriz Sarlo (2007: 24-25), autora que problematiza a confiança que nossas sociedades moderno-contemporâneas depositam sobre o eu,

Não há testemunho sem experiência, mas tampouco há experiência sem narração: a linguagem liberta o aspecto mudo da experiência, redime-a de seu imediatismo ou de seu esquecimento e a transforma no comunicável, isto é, no comum. A narração inscreve a experiência numa temporalidade que não é a de seu acontecer (ameaçado desde seu próprio começo pela passagem do tempo e pelo irrepetível), mas a de sua lembrança. A narração também funda uma temporalidade, que a cada repetição e a cada variante torna a se atualizar.

A memória compartilhada durante o processo de entrevista constituiu-se no caminho pelo qual as mulheres produziram um sentido para suas trajetórias reprodutivas depois de transcorridos cerca de trinta anos entre o evento da esterilização cirúrgica e a narrativa a seu respeito. A memória ativada depois de tantos anos traz para o primeiro plano da narrativa as trajetórias dessas mulheres em relação à maternidade que exerceram no passado e os efeitos trazidos por esse exercício para suas trajetórias de vida até o presente. Nessa narrativa também são lembrados os lugares ocupados por outros atores significativos no projeto de maternidade. Nesse sentido, as mães, os companheiros e as filhas são referências importantes na construção da memória da reprodução. Outro aspecto relevante acionado nas narrativas das mulheres diz respeito à busca e à negociação com agentes de saúde, sobretudo os médicos, para a realização da cirurgia de esterilização. As narrativas produzidas pelas mulheres a partir da pesquisa abordam os desafios enfrentados por elas na tentativa de controlar a quantidade de filhos. Não estava em questão ser ou não ser mãe, mas, sim, o número ideal de filhos de acordo com um modelo de família almejado. Essa contabilidade foi feita ao longo do tempo da relação conjugal e ao sabor de fatores nem sempre previsíveis. As mulheres elaboram essa memória e, por meio dela, constroem um sentido positivo para suas trajetórias como mães. Falar sobre esterilização é, para elas, falar sobre uma opção possível na conjuntura em que viviam para realizar o projeto de ser uma "mãe responsável".

\section{O COMPANHEIRO, AS MÃES E AS FILHAS}

Minha mãe dizia: "Vai ligar que o seu marido não tem juízo". Porque, naquele tempo, ele saía, chegava quatro horas da manhã dizendo que estava trabalhando no banco, imagina! Ele dizia que estava trabalhando. Minha cunhada dizia: 
"Você é boba". Até cheguei a ir no trabalho dele. Mas, não deu. Eu ia fazer tudo, mas meu cunhado impediu: "Não faça isso! Num banco não, que é feio". Aí, eu ficava com raiva dele. Aí, minha mãe dizia assim: "Olha, você era para ter só uma filha. Ele não tem juízo, não tem hora para chegar em casa. Onde já se viu?” Por isso que eu resolvi ligar (Iara, ${ }^{6} 64$ anos, três filhos).

Jocélia (68 anos, oito filhos) lembra-se das discussões que travava com seu falecido marido, que era absolutamente contra a esterilização: "meu marido é daquela época de antigamente, muito ignorante. Ele falava: 'mulher que faz isso [ligadura] é porque quer dar o rabo na rua'”. Seu desejo de não ter mais filhos era para poder ter mais tempo para se cuidar e cuidar dos filhos que já tinha. Em sua opinião, a quantidade de filhos que teve acabou com seu bem-estar físico e sua aparência, o que fez com que ela se sentisse "humilhada" e menosprezada pelo marido. Jocélia conta que alerta suas noras e filhas.

Eu explico para elas a minha situação para elas não passarem por essa situação. Que parece nada não, mas os filhos sempre puxam os pais. [Mas, que situação é essa que a senhora não quer que elas passem?] O que eu passei, ser humilhada. Porque tendo muito filho, elas não têm tempo nem de cuidar delas. Eu não cuidei de mim. Tanto que não cuidei que meus dentes doíam, eu arrancava porque não tinha dinheiro para ir num dentista, para botar uma dentadura. Eu me acostumei a ficar sem dente mesmo. Aí, eu explico para elas isso. "Se cuida porque as lá da rua eles acham uma gracinha, viu? E você, em casa toda mulambenta, suja, com cabelo duro." Aí já viu, arruma até desculpa que está arrumando na rua porque a mulher em casa não se cuida.

Para conseguir a autorização do marido para a esterilização, Jocélia acionou sua sogra, que intercedeu a seu favor.

Eu queria, era isso mesmo que eu queria [fazer a ligadura de trompas]. Eu queria ficar livre porque meu marido até se morresse, eu acho que ia me deixar grávida, porque o homem era muito fértil. Mas, aí a mãe dele ficou do meu lado. Ela disse: "Newton, deixa ela fazer esse trabalho aí, porque vai ser bom para você mesmo. Vai ser menos filho, entendeu? Por que você é o quê? Você é um... simplesmente um motorista, motorista não ganha tanto assim. A mulher tem que trabalhar para poder te ajudar. Aí, quer dizer, com muito filho, como é que ela vai poder trabalhar?" Aí ele se conformou, a mãe dele falando, porque comigo não.

A qualidade da relação com o parceiro foi um elemento que se destacou nas lembranças de diferentes mulheres a respeito do contexto que envolvia a decisão pela esterilização. As considerações sobre o valor do homem como marido permeiam a justificativa da escolha pelo fim da capacidade reprodutiva. A suspeita de que o companheiro pudesse ter outras mulheres ou a ideia de que ele passasse tempo demais fora de casa em horários vistos como impróprios foram elementos considerados na hora de avaliar se era ou não adequado continuar a ter filhos com ele. A interferência de outras mulheres da 
parentela é bem-vinda. Mães e sogras podem ser aliadas importantes para a tomada dessa decisão. Da mesma forma, ao aconselhar filhas e noras, Jocélia reflete sobre sua própria experiência. Não vale a pena sacrificar-se tanto para ter filhos. Jocélia foi a entrevistada com menor escolaridade e maior número de filhos.

De outra perspectiva, mas ainda em relação à qualidade do parceiro e da relação, nos conta Lídia (66 anos, hoje divorciada do pai de suas duas filhas):

As meninas nasceram com o maior amor, o maior carinho de ambas as partes. Eu quis muito tê-las e tê-las com ele. Até porque quando a caçula nasceu, eu tinha 34 anos. Eu vou ligar minhas trompas porque não quis mais filho com ninguém, só queria ter com ele, entendeu? [Por quê?] Não sei. Primeiro porque dois estava bom, duas estava bom. Segundo, eu botei na cabeça que, se eu me separasse dele, eu não ia querer ter mais filho com ninguém. Eu não sei, foi uma doideira minha, entendeu? E foi a melhor coisa que me aconteceu. Quando eu juntei com essa outra pessoa, no início, tudo bem. Mas, depois eu vi quem era essa pessoa. Era maluco, cara! Me maltratava, Deus me livre que eu tivesse tido filho com ele! Ia ser uma coisa horrível! E, graças a Deus, eu tinha ligado minhas trompas, parece que eu estava adivinhando.

Após a experiência de um relacionamento conturbado, Lídia pode reavaliar a escolha anterior. Em sua visão, ela pôde escolher o pai ideal para suas filhas, mesmo que a relação amorosa não tenha permanecido. Escolher com quem ter filhos parece ser tão relevante quanto escolher quantos filhos ter Avaliações sobre o caráter do parceiro pesam na decisão de manter ou não a capacidade reprodutiva. Em análises sobre a prática do aborto (Fachel Leal, 2000), identificou-se no discurso das mulheres algo similar: um dos fatores que contribuem para a decisão de não levar uma gestação a termo é a expectativa em relação ao parceiro, se ele assume ou não a gravidez.

Nos relatos das mulheres entrevistadas também surge o contraste entre a geração delas e a geração mais jovem, a de suas filhas e noras. Algumas entendem que as mulheres que buscam hoje em dia a esterilização estão em situação pior, posto que desde a regulamentação do planejamento familiar no Brasil, feita em I997, há uma série de regras a cumprir nos Serviços de Saúde em relação à esterilização voluntária. Essa constatação contrasta com a época, vivenciada por elas, em que havia maior liberalidade em relação à negociação da cirurgia com o médico. Um dos efeitos dessa liberalidade nas negociações entre médicos e pacientes foi o aumento da escolha pela cesariana como forma de parto. O último filho chegava por cesárea para que a esterilização pudesse ser realizada no mesmo procedimento cirúrgico.

Ao se referir à esterilização, as entrevistadas tendem hoje a vê-la como uma solução para mães consideradas "incapazes".

Eu acho uma boa opção a ligadura porque tanta criança nesse mundo aí sofrendo. Há mulheres aqui que têm três, quatro filhos e não têm chance de ligar, não têm chance. A P. aqui, ela não teve como ligar. Já teve o quê? Cinco filhos e 
nunca quiseram ligar ela, dizem que ela é nova (Jussara, 59 anos).

Tem uma menina lá, ela tem 22 anos e quatro filhos. Essas crianças não têm pai. Ela bate nos bebês porque não tem paciência, usa droga. Então eu acho assim, o governo devia fazer uma lei dentro do hospital. Ou então botasse assim uma assistente social para saber quantos filhos tem. "Ah, tem dois. Onde mora?" Procurar saber a vida daquela pessoa e ligar aquela pessoa, fazer uma ligadura (Carolina, 5I anos).

$\mathrm{Na}$ entrevista as mulheres, em sua maioria, afirmaram ter tido conversas com as filhas sobre contracepção no momento da iniciação sexual. Poucas registram diálogos sobre o assunto quando a filha já é considerada mulher adulta, ou seja, quando já está casada e tem seu próprio núcleo familiar.

Eu sou uma mãe muito alienada quanto a isso, muito mesmo (Ana, 55 anos).

Isso é um assunto que eu não procuro saber não (Jussara, 59 anos).

A gente não é muito assim de conversar não porque os filhos não gostam de conversar muito com os pais não (Jocélia, 68 anos).

Uma pista para entender tal atitude pode estar no diferencial educacional entre mães e filhas. Todas as entrevistadas que afirmaram não manter mais conversas com as filhas sobre contracepção são mulheres de escolaridade mais baixa do que a das filhas. Quando a escolaridade da filha ultrapassa a da mãe e ela se torna adulta, ou seja, casada, as conversas sobre contracepção deixam de fazer sentido. Essa indicação merece outro tipo de tratamento de pesquisa para que possa ser verificada, posto que uma das hipóteses que sustenta a ideia de que existe uma "cultura de esterilização feminina" afirma que a disseminação da prática se dá entre gerações de mulheres de uma mesma família ou de parentes afins (Berquó, I999).

Não é raro, entretanto, mães e filhas trocarem informações a respeito da esterilização; no caso de Margarida (72 anos), o resultado foi o incentivo da mãe à adoção dessa forma de encerramento da reprodução pela filha. Em seu relato, Margarida reconhece que "esterilização é pecado", mas, mesmo assim, apoiou sua filha quando ela decidiu se operar. Em sua opinião, Deus dá a capacidade de procriar, mas

Deus não manda; Deus quer que todo mundo tenha um salário digno de se viver. Nós não temos. Vou botar criança no mundo para sofrer? Porque não está fácil, não. A pessoa tem o filho, tem os alimentos, mas o estudo está matando, está sufocante! Nos colégios, agora só se fala em briga. Bota no particular que é mais... Mas tem que ter grana. Criança no particular é diferente o convívio. No público, pega fogo!

\section{OS SENTIDOS DA ESTERILIZAÇÃO}

Analisada do ponto de vista das mulheres que realizaram a cirurgia, a esterilização feminina mostra ampla diversidade de significados e seus possíveis impactos na vida das mulheres. Ao explorar a memória sobre a reprodução e a 
contracepção de mulheres mais velhas, produzimos um tipo de narrativa que reflete os dilemas enfrentados por uma geração. Trata-se da geração que deu início à prática da esterilização no Brasil e que precisou lidar com aspectos das relações de gênero e com a ausência de políticas de saúde reprodutiva nos anos I 970 e I980.

Naquele momento, também se disseminava um novo modelo de família conjugal, caracterizado pelo avanço do trabalho feminino fora do lar e pela diminuição do número de filhos. A família mínima passou a ser sinônimo do compromisso com um projeto de individualização (Velho, I994). As mulheres foram agentes desse processo.

Há um interessante contraste estabelecido entre a pouca clareza na fala das mulheres entrevistadas sobre quando iniciar o ciclo reprodutivo e a absoluta certeza sobre quando parar de ter filhos. O primeiro filho raramente é mencionado como um "filho planejado", essa ideia está ausente do discurso das mulheres. Já o último filho vem marcado pelo desejo e pelo projeto claro de encerramento da reprodução. Como se o que pudesse ser, de fato, planejado fosse o fim da carreira reprodutiva e não o seu início (Cabral, 20I I). Há uma valorização da escolha pelo encerramento do tempo reprodutivo (visto como um tempo de controle ou de tentativas de controle) que acompanha a ideia de que esse tempo se esgota. A cirurgia para laqueadura simboliza esse esgotamento, quase como um rito de passagem para outro tempo sem preocupações com gravidez. Nessa geração de mulheres, não há referência à participação dos homens na decisão a respeito do encerramento da reprodução.

A quantidade de filhos que compõem a família é avaliada ao longo da vida conjugal. O ponto final no período de procriação estabelece os limites da família mínima. Uma frase constantemente repetida nas entrevistas era "quem tem um não tem nenhum; quem tem dois, tem um". Esse ditado revela a noção de que o filho único deve ser evitado, e as ideias de que um só filho representa um risco e de que ter irmão é benéfico para as crianças foram lembradas nas entrevistas. A morte dos filhos é tema difícil, doloroso. Algumas entrevistadas já haviam passado por essa experiência e, embora tenham dito que um filho não substitui outro, acabar sem filho nenhum era visto como uma experiência que ninguém desejava. Todas me perguntaram se eu era mãe. Quando eu afirmava que era mãe de um menino, indagavam em seguida: "Por que um filho só? Filho único não é bom".

Não aconteceu nada desse negócio de engordar, de sentir falta de alguma coisa, não senti nada. Para dizer a verdade, é uma coisa que nem me lembro, nunca pensei, nem lamuriei, nada, nem pensei. Foi tranquilo. Graças a Deus os três (filhos) estão vivos, não tenho nem do que me arrepender. Mas, mesmo assim: um filho não substitui o outro (Ana, 54 anos).

As mulheres não elencaram o custo material de criar filhos como um motivo considerado por elas quando avaliaram a esterilização como forma de 
interrupção do ciclo reprodutivo. Embora o tema dos custos trazidos pela criação dos filhos seja considerado quando falavam sobre suas famílias de origem ou sobre a situação de quem tem filhos nos dias atuais, ao relatar a sua própria história a questão financeira aparece diluída na narrativa. O tempo dedicado ao cuidado dos filhos pequenos tem mais relevância em suas falas e é o que parece ter ficado marcado na memória. O controle do tamanho da prole passa pela avaliação do tempo investido no cuidado das crianças e também pela avaliação subjetiva do corpo como um corpo para a reprodução. As gestações e os partos são experiências vividas de maneira singular por essas mulheres. Há relatos mais e menos felizes das gestações e dos partos; mais e menos dolorosos. A gestação e o parto são singularizados, assim como são únicos os filhos gerados, cada um com seu jeito, suas histórias particulares. A compreensão dessa geração de mulheres é de que existe um período propício na vida para ter filhos, e esse período se encerra. A esterilização por seu caráter irreversível simboliza esse encerramento.
A gente tinha resolvido esperar um pouco para ter os meninos. Mas, depois de três ou quatro meses [de casados], naquela época eu não tomava pílula, tinha que fazer conta, hoje pode, amanhã não pode, e um dia... Ah! Vamos liberar essa história! Aí o Marcelo veio, e foi ótimo. Olha, quer ver, eu fiz um ano de casada no dia 20 de março e ele nasceu no dia 28 de julho. Aí, três meses depois, eu des- cobri que estava grávida de novo. Então a diferença do Marcelo para o Luis não é nem de I I meses. O Luis aconteceu, e foi ótimo. Depois que o Luis nasceu, eu fi- quei um tempo tomando pílula até que um dia eu resolvi, fui eu mesma, eu disse: "Ah! Queria tanto ter uma menina! Quem sabe agora vem?" A gente estava com a vida organizada, meu marido estava com um trabalho razoável, e eu estava tra- balhando, vamos partir para o terceiro. E aí veio a Simone, linda! Aí eu resolvi terminar porque três já estava de bom tamanho (Suzana, 72 anos).

Quando se recorda da esterilização, a fala reflete um momento de saturação. A constatação de que se chegou ao fim de uma etapa da vida. Podemos comparar essa ideia de saturação com a análise de Marilyn Strathern (I 995: 305) a respeito da polêmica da "síndrome do nascimento virgem" na Grã-Bretanha. ${ }^{7}$ Trata-se de "mulheres solteiras sem nenhuma experiência sexual e sem nenhuma intenção de ter relação sexual e que desejam ter filho por meio da concepção assistida". Essas mulheres foram criticadas não por desvincular a relação sexual da reprodução, mas sim por desvincular a reprodução da relação sexual. Ao anular o sexo e abraçar a reprodução, elas provocaram um imenso debate. Nesse caso as mulheres foram questionadas sobre sua capacidade relacional, e a ideia do feminino foi medida pela expectativa de criação de vínculos. No caso das entrevistadas desta pesquisa, os vínculos foram trazidos como prova da responsabilidade materna e como um aval para a separação estabelecida entre sexo e reprodução. Justamente pelo fato de que já eram mães na ocasião relembrada, a opção pela esterilização cirúrgica lhes parecia legítima. Era uma demonstração de responsabilidade e compromisso com o futuro 
da prole que já existia. A desvinculação definitiva entre sexo e reprodução emergia assim justificada para mulheres que já haviam cumprido a tarefa reprodutiva. Uma mãe responsável deve saber a hora de parar de ter filhos e continuar sexualmente disponível para seu parceiro. No contexto em que estavam inseridas, a cirurgia era a maneira definitiva de afirmação da maternidade responsável, já que a pílula e outros métodos contraceptivos não eram plenamente confiáveis, nem de fácil acesso.

Em algumas situações, o diagnóstico médico foi recordado como um estimulador da decisão pela esterilização endossando a ideia de maternidade responsável:

Devido a eu já ter três barrigas abertas [cesáreas], que era tudo no mesmo lugar, aí o médico falou que eles tinham que ligar, que eu já tava de idade e já tinha três. Eu já tinha passado dos 40, aí era risco, aí ele disse que ia ligar e nem cobrou nada, não (Margarida, 72 anos).

Por causa de um diagnóstico de câncer, Cida (58 anos) se viu diante de uma situação dramática:

Eu não podia tomar anticoncepcional por causa dos hormônios, então, quer dizer, você fica naquela. Quando foi em dezembro, eis que eu apareço grávida. Jesus! Mas, cara, eu me prevenia, eu tinha sexo com camisinha. Gente, onde foi que eu errei? Será que o troço arrebentou e eu não percebi? Nós não percebemos? Agora você analisa comigo, esse é um segredo que eu nunca abri para ninguém, eu nunca contei porque eu acho que foi uma coisa muito chata e eu peço muito perdão a Deus. É aquilo, o médico chega para você e fala assim: "olha, está nas suas mãos, você pode levar essa gravidez adiante, mas você pode ter um outro problema no câncer, pode te surgir um nódulo em outro lugar". Aquilo, minha cabeça rodou. Eu falei: gente, e agora? Eu tenho uma filha pequena para criar.

Cida e seu marido ficaram muito abalados diante do problema. Mas, com o aval do médico, optaram por um aborto seguido de laqueadura para evitar novas gestações arriscadas.

Outro fator que aparece informando o contexto da decisão pela laqueadura é o da idade; a constatação de que já se é "velha demais" para ainda querer ter filhos.

Conversei com meu marido, conversei com meu médico também. Ele achou que eu já estava [velha] também... Quando eu fui ter o F., eu já estava com 3i anos. Aí, na época, eu já tinha medo também, aquelas coisas, que depois de... é muito perigoso ter filho. Eu casei com 24. Mas, eu demorei porque eu achava, sempre achei, que primeiro a gente tem que ter um suporte para depois ter filho, para depois não ficar naquele desespero. O único que foi contra foi o pediatra deles. "Como você pode fazer isso? Seu útero está perfeito, está tudo perfeito". Foi uma decisão pensada. Talvez, se eu tivesse tido eles mais cedo, eu talvez tivesse tido uma terceira gravidez. Mas, para mim, o que pesou mesmo foi a idade, pesou mesmo. Se eu tivesse tido um filho logo que eu casei, talvez eu tivesse três. Mas, eu achei que já estava velha, aquela coisa toda... naquela época... (Fátima, 59 anos). 
A bibliografia que discute a regulação da fecundidade no Brasil tende a apontar as instituições de saúde e seus profissionais, sobretudo os médicos, como os principais agentes que influenciaram o processo de queda da natalidade (Correa, 200I; Loyola \& Quinteiro, I982; Vieira, I990). A importância adquirida pelo discurso médico sobre o assunto é atribuída à ausência de políticas públicas que regulem o planejamento da concepção como direito reprodutivo. Segundo Correa (200I: 56), "A carência de políticas demográficas promove a absorção pelo modelo médico de questões que, em tese, deveriam ser objeto daquelas políticas".

O modelo médico do qual se fala é retratado como sendo responsável pelo tratamento tecnicista/moralista dado às questões de saúde da mulher. Esse tratamento promoveria distorções no acesso e na forma de utilização dos recursos contraceptivos. A promoção de uma "cultura da esterilização feminina” (Berquó, I993) guardaria relações com a difusão desse controle médico-técnico sobre os corpos das mulheres.

A disseminação de ideias e práticas referentes ao desenvolvimento e à necessidade de tecnologia realizada pelas entidades de planejamento familiar e pelas escolas médicas foi fundamental para consolidar e ampliar a medicalização no que se refere ao controle da reprodução. São ideias e práticas que, tomando o corpo feminino apenas do ponto de vista de sua capacidade reprodutiva, na dualidade "ser mãe/não ser mãe", e responsabilizando as mulheres exclusivamente pela prática contraceptiva, transformaram as expectativas femininas em relação à vida reprodutiva. Ou seja, a dor do parto deu lugar a um evento cirúrgico, e a possibilidade de procriar ao desejo da esterilização (Vieira, I999: 75).

Em minha interpretação, essa explicação sobre o poder do discurso médico para moldar os corpos femininos não pode ser compreendida sem considerarmos que a possibilidade de contar com algum recurso médico-tecnológico para interrupção do ciclo reprodutivo - e, sobretudo, de poder pagar por ele - contrasta, na narrativa das mulheres, com as sucessivas experiências de (des) controle da concepção, vividas por elas ao longo da vida. Mesmo no discurso de mulheres com grau elevado de escolaridade e informação, a questão do descontrole da concepção aparece:

Naquela época [anos 1970], a pílula não tinha assim os anos de experiência que tem hoje. Você ficava sempre com medo de te trazer algum problema. O médico mandava sempre interromper, aí vinha o medo de engravidar de novo. [...] Esse negócio de ficar usando tabela era absolutamente ridículo (Suzana, 72 anos).

Sempre evitei, evitei com pílula. Até o dia em que eu fui para [treinamento militar] e lá foram quatro meses internada, com uma alimentação especial, com uma educação física arrojada, aulas de manhã e de noite, provas e uma imposição psicológica gigantesca em cima da gente, e acredito que aquilo ali mudou o meu organismo porque a pílula eu continuei tomando, entendeu? Depois de um mês internada, sem atender telefone, sem ninguém, eles liberaram a gente um fim de semana para vir para casa, mas já o organismo era outro. [...] Eu acredito 
que, a única coisa que eu vejo de diferente foi essa alimentação, essa educação física, esse estresse emocional todo que deve ter mudado alguma coisa, mudou alguma coisa aí eu engravidei (Carla, 59 anos).

Das I5 entrevistadas somente uma narrou sua trajetória contraceptiva enfatizando um controle explícito e bem-sucedido sobre a quantidade de filhos que queria ter e quando ter. Lídia (66 anos) não usou pílula porque se sentia mal, então adotou o diafragma que, segundo seu relato, tinha seus inconvenientes: "Naquela época [anos I970], era diafragma, que era outra coisa chata. Tinha que botar, depois tinha que esperar, depois tinha que tirar, tinha que lavar, aí botava de novo em cada relação. Aquilo eu achava horrível, mas evitei com o diafragma. [...] Quando tirei o diafragma, falei: "agora eu vou querer ter filhos". Teve duas filhas em seguida e fez a laqueadura.

Contrasta também com as experiências de suas mães. Várias entrevistadas espontaneamente relembravam suas famílias de origem e a quantidade de filhos que suas mães haviam tido.

A minha mãe, ela teve sete filhos porque na sua época não tinha esse negócio
de..., como na minha época já teve, e hoje eu acho que mais ainda, esclarecimen-
to médico, como tomar pílula, evitar esse negócio todo. Ela nem sabia direito a
tabelinha, ela não sabia, ela engravidou porque não sabia. Ela mesma dizia: quan-
do eu achava que não era para ter filho, aí eu tinha... (Fátima, 59 anos).
A galinha bota um monte de miolo, tem aquelas nata assim. A mulher quando
nasce já tem, já vem com aquilo, entendeu? A quantidade de coisinha ali, de
frutozinho que a pessoa vai ter filhos. Então a minha mãe, e outras e outras,
tinha filho até o último grão. Aí quando não vinha é porque a coisa não debandou
(Margarida, 72 anos).

É como se à geração das mulheres pesquisadas tivesse sido dada a chance de não passar pela mesma aflição sofrida por suas mães, de não precisar ter "filhos até o último grão". Elas se veem diante da possibilidade de viver a maternidade em outro patamar, podendo controlar a própria reprodução. Esse contraste estabelecido entre elas e a geração anterior de suas mães é importante, pois coloca em tela a percepção de que estavam diante de uma oportunidade até então inexistente. As dificuldades enfrentadas com o uso da pílula podiam ser evitadas, adotando a esterilização.

O fato de narrarem a negociação direta com o médico também confere à esterelização uma aura de "decisão individual" e de "afirmação de si". As lembranças dos diálogos com os médicos até a realização do procedimento durante as entrevistas vinham cercadas de expressões que enfatizavam a vontade determinada da narradora nesse momento de sua vida. O próximo depoimento selecionado traz a sensação de vitória sobre os desígnios do próprio corpo.

Não aceitou, não permitiu [referindo-se a seu médico]. Então, a C. nasceu e eu disse: "Mas eu quero aproveitar para fazer a ligadura". Ele disse que de jeito nenhum, que eu era muito nova. Eu disse: "Mas, eu não quero mais, doutor." Aí, o que é que ele falou pra mim? "Eu acho um absurdo, e se morrer uma?" Eu falei: 


\begin{abstract}
"Isso para mim não é argumento. Eu tenho duas filhas, se elas morrerem, nenhum filho vai substituir nenhuma delas, de maneira que esse argumento, para mim, não é válido. Não é válido mesmo". Mas, ele não quis fazer a ligadura. Então, o que aconteceu? Depois que a C. nasceu, eu esperei um ano, arrumei outro médico que aceitou fazer (Lídia, 66 anos).

A gente fica naquela ansiedade para ligar, pra não ter mais. Aí, quando a gente consegue um médico para fazer o tratamento, aí a gente vai fundo [...]. Eu fui lá ver, fiz pesquisa, para poder me entrosar direitinho. Para saber se era confiável, e era bom o médico lá. Era uma maneira de ele ajudar as mulheres, ele fazia assim num valor mais baixo. Ele fez a parte dele de ajudar as mulheres, até tinha bastante mulher lá, fazendo a ligadura (Maria, 55 anos).
\end{abstract}

Certamente, as circunstâncias que cercaram a decisão pela esterilização foram percebidas como não controladas pelas mulheres, quais sejam: idade, condições de saúde, qualidade da relação conjugal, incertezas geradas quanto à eficácia dos métodos contraceptivos. Porém, as ações de procurar um médico, de negociar com ele o pagamento e as condições da cirurgia foram compreendidas pelas mulheres como a forma encontrada para fazer frente às adversidades enfrentadas. Em uma situação cercada de limitações, a esterilização aparece em suas falas como uma solução inovadora, segura e definitiva. Algo que podia afastar o fantasma da incerteza. Nesse sentido, como outras autoras já fizeram (Cabral, 20I I; Dalsgaard, 2006), é preciso matizar a ideia de controle médico sobre os corpos das mulheres. As entrevistadas revelaram em seus relatos o desejo de se tornar agentes na condução de seus projetos de maternidade, e a esterilização foi uma ação efetuada com vistas à construção desse projeto.

O projeto de encerramento da capacidade reprodutiva passa pela avaliação da mulher a respeito das dificuldades enfrentadas cotidianamente para manter a família e para preservar seu lugar de "mãe responsável". Não se trata de uma visão em que o valor preponderante seja a autonomia do corpo feminino percebido como independente dos vínculos de parentesco e de afinidade que o marcam e lhe conferem lugar social. Para essa geração de mulheres, a reprodução emerge como um encargo assumido por elas dentro de um projeto conjugal-familiar.

Quando eu fui chegando lá [no hospital], aí o médico foi chegando de carro, parece que foi Jesus que botou ele no meu caminho. Aí eu cheguei e falei, perguntei se ele era médico de grávida e ele falou que era. Aí, eu expliquei a situação, conversei com ele, perguntei por quanto ele ligava, porque eu já tinha cinco filhos, já tinha tido dois abortos. Então, queria fazer a ligadura porque eu não queria mais filho, não dava. Aí, ele deu o preço, que eu nem lembro mais. Aí ele deu o preço, fui pagando, pagando e quando fiz nove meses... Aí eu liguei para ele e ele falou que eu fosse andando para o hospital que ele vinha. Eu fui para o hospital, aí ele chegou; mais ou menos ir:30 eu fui para a mesa de cirurgia e ele fez a ligadura, fez a cesárea e ligou. Eu até perguntei para ele assim: "Doutor, o senhor tem que cortar, pelo amor de Deus, que eu não quero mais filho não". "Não, pode deixar que eu já cortei" (Cecília, 69 anos).

A menopausa veio muito cedo, eu tinha 38 anos. Então para você trocar o DIU, 
eles querem que você esteja menstruada. Aí eu percebi que o negócio não estava bom porque eu não ficava menstruada para botar o DIU outra vez, e o maridão esperando. Aí o negócio demorou tanto, que eu disse: "Isso está errado". Aí eu fui para a ginecologista, expliquei, e ela veio com aquela conversa: que meu marido pode morrer, que eu posso me arrepender, ele [o marido] que agora está calmo pode querer outro filho, que a vida dá voltas, que o meu filho pode morrer e eu querer outro herdeiro... E eu disse: "Não, não; eu quero fazer laqueadura tubária porque eu não quero me arriscar de engravidar por causa do nada. Não, eu não quero isso para mim de jeito nenhum", aí fiz a laqueadura (Carla, 59 anos).

O caso de Jocélia (68 anos) é emblemático nesse sentido. Ela sofreu duas intervenções cirúrgicas para esterilização. A primeira não funcionou e ela engravidou novamente. Foi somente na segunda tentativa, com outro médico, que seu projeto de encerramento do ciclo reprodutivo vingou.

Aí eu procurei o médico que fez a minha ligadura, e ele falou que eu estava com mioma, não estava grávida não. Eu falei: "Bom, ainda bem". Mas, também não é uma boa porque quem está com mioma tem que operar. Aí ele pegou e disse assim: "Bom, eu vou fazer o seguinte, vou passar a senhora para outro médico e a senhora vai ver o que está acontecendo". Aí, quando eu fiz a ultra, confirmou que era uma gravidez. Aí foi quando o médico de lá falou para mim: "Olha, estou vendo que não adianta ligadura para a senhora, que a senhora vai arrebentar novamente. O negócio é tirar essas trompas fora". Eu disse: "Ih, doutor, já era para ter tirado. Pelo amor de Deus, já estou cansada, é muita luta, muito filho, muito trabalho". Aí ele falou: "A senhora pode deixar que não vai ter mais filho não. Se a senhora tiver filho, eu rasgo meu diploma".

O tema do arrependimento pós-laqueadura tem sido tratado pela literatura médica especializada; em geral, são poucos os registros de arrependimento. Na literatura médica, a investigação sobre esse assunto preocupa-se em identificar os fatores que contribuem para o arrependimento. O mais comum, segundo os estudos realizados, seria a idade da mulher por ocasião da realização da cirurgia: quanto mais jovem, maior a probabilidade de arrependimento (Campos de Carvalho et al., 2006). Nesse conjunto de entrevistas, as circunstâncias da laqueadura foram evocadas e trazidas novamente à tona. Ao refazer o caminho reprodutivo mediante narrativas de memória, as mulheres tenderam a se apresentar como satisfeitas com a decisão que tomaram ou, pelo menos, resignadas com ela depois de decorridos tantos anos.

\section{CONSIDERAÇÕES FINAIS}

A motivação desta pesquisa foi rever o momento de introdução da prática da esterilização feminina no Brasil pela perspectiva das mulheres que o vivenciaram. A abordagem geracional permite realizar contrastes entre diferentes experiências, e, com ela, a reprodução e a contracepção ganham sentidos diferentes. A geração entrevistada, que inaugurou e encerrou sua vida reprodutiva nos anos I970 e I980, esteve no centro de uma mudança radical dos padrões de fecundidade no Brasil. As taxas de fecundidade caíram, e baixou também a 
faixa etária em que as mulheres passaram a ter seus filhos. Nessa mesma época, começaram a surgir iniciativas concretas em torno da defesa dos direitos reprodutivos das mulheres. A década de I 990 viria a ser crucial e assistiria ao aprofundamento de uma agenda comprometida com os direitos das mulheres. A cada ano, novas tecnologias contraceptivas passaram a surgir no mercado de medicamentos. No entanto, o acesso a elas ainda não foi generalizado, e o assunto permanece envolto em valores morais. Recordemo-nos, por exemplo, da polêmica instaurada em torno da liberação da "pílula do dia seguinte".

A geração que vive atualmente os dilemas da reprodução enfrenta outros desafios: as novas tecnologias reprodutivas surgem como opção para adiar a maternidade, por exemplo, ou configuram um drama para os casais inférteis. Alguns desafios, contudo, se mantêm, sobretudo aqueles referentes às relações entre os gêneros; à responsabilização masculina para com ações contraceptivas, que ainda deixa a desejar. Na percepção das mulheres entrevistadas, a atual geração de mulheres conta com avanços no campo da oferta de alternativas contraceptivas seguras. No entanto, para elas, ao refletir sobre sua experiência passada, a esterilização continua a ocupar o lugar de "melhor solução".

Recebido em 28/04/20I6 | Revisto em I9/06/20I6 | Aprovado em 20/06/20I6

Andrea Moraes Alves é doutora em antropologia pelo Museu Nacional/UFRJ, professora-associada da Escola de Serviço Social da UFRJ e pesquisa relações de gênero e gerações. Sua obra principal, A dama e o cavalheiro: um estudo antropológico sobre envelhecimento, gênero e sociabilidade (2004), é fruto de sua tese de doutorado. 


\section{NOTAS}

I A pesquisa recebeu financiamento da Fundação de Amparo à Pesquisa do Estado do Rio de Janeiro (Faperj) e do Conselho Nacional de Desenvolvimento Científico e Tecnológico (CNPq).

2 Segundo o Dicionário Aurélio, laparoscopia é a visualização da cavidade abdominal mediante o uso de um aparelho de fibra óptica chamado laparoscópio ou endoscópio, que é introduzido no corpo do paciente através da parede abdominal anterior; laparotomia é qualquer incisão destinada a abrir a cavidade abdominal.

3 A Igreja católica era (e ainda é) abertamente contrária à contracepção, sobretudo a artificial. Na Constituição Federal de I988, o planejamento familiar foi incluído como direito social. Sua regulamentação foi feita em I997, e nela consta a esterilização voluntária para homens e mulheres. Antes da CF/88, o único instrumento legal que arbitrava sobre a esterilização era o código penal. Pelo código, a esterilização poderia ser classificada como crime de lesão corporal, exceto se fosse comprovada sua realização para fins terapêuticos.

4 Os índices de mortalidade materna caíram em 20 I I no Brasil. Mas, o país ainda se encontra distante das metas aprovadas pela ONU. Disponível em: <www.observatoriodegenero.gov.br>. Acesso em 3 abr. 2014

5 O trabalho de Joana M. Pedro se destaca por ser um dos poucos que aborda mulheres com níveis mais altos de escolaridade e que a autora classifica como pertencentes às camadas médias urbanas. Em minha pesquisa, foram incorporadas mulheres com perfis educacionais e ocupações distintos. Houve variações em dois aspectos: repertório contraceptivo (mais variado entre aquelas com mais alta escolaridade) e referência à prática do aborto (mais comum entre as mulheres com baixa escolaridade).

6 Os nomes das entrevistadas foram alterados.

7 Agradeço a Marcelo Tavares Natividade a lembrança desse texto de Strathern para enriquecer a análise do material de pesquisa. 


\section{REFERÊNCIAS BIBLIOGRÁFICAS}

Alvarenga, Augusta Thereza de \& Schor, Néia. (1998). Contracepção feminina e política pública no Brasil: pontos e contrapontos da proposta oficial. Saúde e Sociedade, 7/I, p. 87-IIO.

Berquó, Elza. (I999). Ainda a questão da esterilização feminina no Brasil. In: Giffin, Karen \& Costa, Sarah Hawker (orgs.). Questões da saúde reprodutiva. Rio de Janeiro: Fiocruz, p.II3-I 26.

Berquó, Elza. (I 993). Brasil, um caso exemplar, anticoncepção e partos cirúrgicos, à espera de uma ação exemplar. Estudos Feministas, I/I, p. 366-38I.

Berquó, Elza \& Cavenaghi, Susana.(2003). Direitos reprodutivos de mulheres e homens face à nova legislação brasileira sobre esterilização voluntária. Cadernos de Saúde Pública, I9 (Suplemento 2), p. s44I-s453.

Bourdieu, Pierre. (2006). A ilusão biográfica. In: Ferreira, Marieta de Moraes \& Amado, Janaína (orgs.). Usos e abusos da história oral. Rio de Janeiro: Ed. FGV, p. I83-I92.

Cabral, Cristiane da Silva. (20I I). Práticas contraceptivas e gestão da heterossexualidade: agência individual, contextos relacionais e gênero. Tese de doutorado. Programa de Pós-Graduação em Medicina Social/Uerj.

Caetano, André Junqueira. (2010). Contracepção está associada às mudanças do país. O Estado de S. Paulo, Caderno Vida, 8 de maio, p. A24,

Campos de Carvalho, Luiz Eduardo et al. (2006). Número ideal de filhos e arrependimento pós-laqueadura. Revista da Associação Médica Brasileira, 52/5, p. 293-297.

Correa, Marilena. (200I). Novas tecnologias reprodutivas: limites da biologia ou biologia sem limites? Rio de Janeiro: Eduerj.

Dalsgaard, Anne L. (2006). Vida \& esperanças: esterilização feminina no Nordeste. São Paulo: Ed. Unesp.

Diniz, Simone Grilo et al. (200I). Not like our mothers: reproductive choice and the emergence of citizenship among Brazilian rural workers and housewives. In: Petchesky, Rosalind \& Judd, Karen (orgs.). Negotiating reproductive rights: 
women's perspectives across countries and cultures. New York: Zed Books, p. 3i-68.

Fachel Leal, Ondina. (2000). Corpo, sexualidade e aborto. In: Debert, Guita Grin \& Goldstein, Donna (orgs.). Políticas do corpo e curso da vida. São Paulo: Sumaré, p. 89-108.

Faria, Vilmar Evangelista. (I989). Políticas de governo e regulação de fecundidade: consequências não antecipadas e efeitos perversos. São Paulo: Anpocs (Coleção Ciência Hoje).

Fonseca Sobrinho, Delcio da. (I993). Estado e população: uma história do planejamento familiar no Brasil. Rio de Janeiro: Rosa dos Tempos.

Halbwachs, Maurice. (2006). A memória coletiva. São Paulo: Centauro.

Loyola, Maria Andrea \& Quintero, Maria da Conceição. (I982). Instituições e reprodução: estudo da atuação das instituições sociais no processo de reprodução humana. São Paulo: Cebrap.

Minella, Luzinete Simões. (2005). Gênero e contracepção: uma perspectiva sociológica. Florianópolis: Ed. UFSC.

Molina, Aurelio. (I999). Laqueadura tubária: situação nacional, internacional e efeitos colaterais. In: Giffin, Karen \& Costa, Sarah Hawkes (orgs.). Questões da saúde reprodutiva. Rio de Janeiro: Fiocruz, p.I27-I46.

Pedro, Joana Maria. (2003). A experiência com contraceptivos no Brasil: uma questão de geração. Revista Brasileira de História, 23/45, p. 239-260.

Pollak, Michael. (I989). Memória, esquecimento, silêncio. Estudos Históricos, 2/3, p. 3-I5.

Sarlo, Beatriz. (2007). Tempo passado: cultura da memória e guinada subjetiva. Belo Horizonte: Ed. UFMG.

Sarti, Cynthia. (200I). Feminismo e contexto: lições do caso brasileiro. Cadernos Pagu, I6, p. 3I-48.

Scavone, Lucila. (2004). Dar a vida e cuidar da vida: feminismo e ciências sociais. São Paulo: Ed. Unesp.

Serruya, Suzanne. (I996). Mulheres esterilizadas: submissão e desejo. Belém: Naea/Universidade Federal do Pará.

Strathern, Marilyn. (1995). Necessidade de pais, necessidade de mães. Revista Estudos Feministas, 3/2, p. 303-329. 
Velho, Gilberto. (I 994). Projeto e metamorfose: antropologia das sociedades complexas. Rio de Janeiro: Zahar.

Vieira, Elizabeth Meloni. (2002). A medicalização do corpo feminino. Rio de Janeiro: Fiocruz.

Vieira, Elizabeth Meloni. (I999). A medicalização do corpo feminino. In: Giffin, Karen \& Costa, Sarah Hawkes (orgs.). Questões da saúde reprodutiva. Rio de Janeiro: Fiocruz, p. 67-78. Vieira, Elisabeth Meloni. (I990). Prática médica e corpo feminino. Dissertação de mestrado. Departamento de Medicina Preventiva/Faculdade de Medicina/Universidade de São Paulo.

Wong Laura L. Rodriguez \& Perpétuo, Ignez H. Oliva. (2009). Uma visão transversal e longitudinal de quatro décadas de queda da fecundidade no Brasil. In: Ministério da Saúde \& Cebrap. Dimensões do processo reprodutivo e da saúde da criança. Pesquisa Nacional de Demografia e Saúde da Criança e da Mulher - 2006. Brasília: Ministério da Saúde, p. 7 I-86. 


\section{Palavras-chave \\ Gênero; \\ reprodução; \\ esterilização feminina; \\ maternidade; \\ trajetórias de vida e \\ memória. \\ Keywords \\ Gender; \\ reproduction; \\ female sterilization; \\ motherhood;}

life trajectories and memory.

\section{MEMÓRIA DA ESTERILIZAÇÃO FEMININA: UM ESTUDO GERACIONAL}

\section{Resumo}

A geração de mulheres que conheceu a introdução da esterilização feminina como prática corrente no Brasil é o assunto deste artigo. Em entrevistas sobre trajetórias contraceptivas, I5 mulheres de distintos perfis sociais relatam seus percursos reprodutivos até a realização da cirurgia. As entrevistadas submeteram-se voluntariamente à esterilização entre os anos 1970 e I980. Os relatos foram colhidos entre em 20 I I e 20 I 2 na cidade do Rio de Janeiro e compõem o material aqui chamado de "memória da esterilização". A partir das narrativas, dois temas se destacam: a dimensão relacional que marca a decisão pela esterilização e a produção das memórias das mulheres sobre a reprodução e a contracepção.

\section{MEMORIES OF FEMALE STERILIZATION:}

\section{A GENERATIONAL STUDY}

\section{Abstract}

The topic of this article is the generation of women who experienced the introduction of female sterilization as a current practice in Brazil. In interviews on their use of contraceptives, fifteen women from different social backgrounds spoke about their reproductive histories prior to performing the surgery. The interviewees all voluntarily submitted to sterilization between the I970s and I980s. The accounts were collected in $20 \mathrm{II}$ and $20 \mathrm{I} 2$ in the city of Rio de Janeiro and form the material referred to here as 'memories of sterilization.' Two themes emerge from the narratives: the relational dimension influencing the women's decision to undergo sterilization, and the production of the memories of the women concerning reproduction and contraception. 